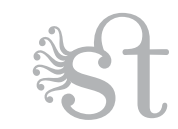

\title{
A ciência e o projeto crítico kantiano
}

\author{
Eduardo Salles de Oliveira Barra
}

\section{Kant et les sciences \\ Organização: S. Grapotte; M. Lequan e M. Ruffing \\ Vrin}

Paris, 2011, 388 págs.

Permitam-me iniciar esta resenha com um relato autobiográfico. Em 2001, concluí a minha tese de doutorado em filosofia, cujo tema foi o envolvimento de alguns filósofos dos séculos XVII e XVIII com as questões científicas de seu tempo. Entre os filósofos focalizados, estava Immanuel Kant (1724,-1804). Uma das grandes dificuldades que enfrentei para levar adiante essa investigação era a quase inexistência de comentários contemporâneos sobre os nexos entre a filosofia kantiana e a ciência do seu tempo. No início da década de 1990, quando iniciei meus estudos, podia-se contar apenas com os dois comentários clássicos sobre o assunto: os livros de Gerd Buchdahl (1988 [1969]) e de Jules Vuillemin (1955). Já naqueles anos, surgiram três novas publicações importantes, o novo livro de Buchdahl (1992), a coletânea de artigos organizada por Robert Butts (1986) e o magnífico trabalho de Michel Friedman (1992), que reputo ser o mais esclarecedor e estimulante estudo sobre o assunto até hoje publicado. Nos anos seguintes à finalização da minha tese, seguiu-se um movimento crescente de interesse pelo tema. Os livros mais recentes de Eric Watkins (2001, 2005) e de Michel Friedman (2013) são efeitos desse movimento.

Creio que o mesmo se possa dizer de Kante as ciências (Kant et les sciences), publicação de 2011, organizada por Sophie Grapotte, Mai Lequan e Margit Ruffing. O livro reúne os trabalhos apresentados na nona edição do Congresso Internacional da Sociedade de Estudos Kantianos de Língua Francesa (SEKLF), ocorrido em setembro de 2009 na Universidade de Lyon III - Jean Moulin, cujo tema central foi o "estatuto da ciência e das ciências na filosofia de Kant" (p. 11). O primeiro aspecto que chama a atenção no projeto editorial de Kant e as ciências é aquele que não deve ter passado despercebido ao leitor atento no próprio enunciado do tema central do congresso, qual seja, a singularidade versus a pluralidade com respeito à ciência (ou seria "às ciências"?). Nisso consistirá grande parte do meu comentário a seguir. Mas, antes dele, devo prosseguir 
com mais alguns detalhes desse projeto editoral, entre cujas motivações certamente também encontraremos as incursões pioneiras de Buchdahl e Vuillemin e, ainda antes deles, Adickes (1924) nesse campo de estudo.

Para fins da publicação dos seus anais, o tema geral do congresso foi dividido em três eixos: (1) a teoria crítica e transcendental kantiana do conhecimento geral, (2) a articulação entre a primeira Crítica e os Prolegômenos com a pluralidade de ciências particulares e (3) "os saberes científicos que Kant mobiliza e para cujo progresso, eventualmente, contribui, ao realizar seja uma fundamentação seja uma crítica..." (p. 12) Os trabalhos relativos aos dois primeiros eixos foram, então, publicados no primeiro volume dos anais, volume esse intitulado Kant e a ciência (Kant et la science). O segundo volume, justamente este aqui resenhado, intitulado Kant e as ciências (Kant et les sciences), reúne os artigos incluídos no terceiro e último eixo temático.

Sobre os trabalhos reunidos nesse volume, os editores esclarecem que se trata de estudos

consagrados às diversas ciências que Kant pretende considerar, [percorrendo esse conjunto] não à exaustão, mas na sua maior completude possível, incluindo metafísica, lógica, matemática, teologia, ciências da natureza (física, química, biologia, geografia física, história natural, cosmologia, astronomia) e ciências do homem e do espírito (antropologia, psicologia, moral, direito) (p. 12).

Um projeto que, em linhas gerais, verifica-se integralmente realizado à simples inspeção do índice dos capítulos e seções em que se dividem as 388 páginas da publicação. Há, ao menos, um capítulo destinado à análise do envolvimento de Kant com cada uma das ciências acima nomeadas. O espaço destinado a cada uma delas é, entretanto, desigual. Questões sobre a lógica e a matemática ocupam quase um terço do livro. As ciências da natureza ocupam outro um terço. $\mathrm{O}$ terço seguinte fica dividido entre dois blocos mais ou menos coesos, as ciências da vida (sciences du vivant) e a estética (enquanto se relaciona à teleologia da natureza), de um lado, as ciências do homem, de outro lado. As eventuais desigualdades de espaço destinadas a cada uma dessas grandes áreas são plenamente compreensíveis, na medida em que refletem os interesses desiguais do próprio Kant acerca de cada uma delas. Tomadas conjuntamente com as ciências da vida e teleologia natural, as ciências da natureza ocupam mais da metade da publicação, cerca de 190 páginas. Isso, naturalmente, reflete o estado de amadurecimento que essas disciplinas científicas encontravam-se à época de Kant e, assim, o quanto elas lhe chamaram a atenção em vista dos seus interesses específicos.

Mesmo admitindo que as desigualdades de tratamento reflitam as desigualdades de interesse do próprio filósofo, algo parece ainda desconcertante nessa despro- 
porcionalidade, se a encaramos de um ponto de vista mais conceitual. $\mathrm{O}$ aspecto conceitual a que me refiro é relativo ao fato de o tratamento que Kant dispensou às várias ciências não se destinar apenas a reconhecê-las e explorá-las como um dedicado homem das Luzes o faria. Como os próprios autores lembram (p. 12), Kant reprova certas consequências que D'Alembert retira do "mapa mundi das ciências" construído na Encyclopédie em 1751. Longe de Kant, portanto, reduzir o seu interesse pelas ciências a um motivo meramente "enciclopédico". Suas pretensões vão bem além disso. Ele parece querer mesmo regular o que pode haver de propriamente científico em seja lá qual for o tipo de crença pretensamente justificada e verdadeira. Aqui, as desigualdades deixam de ser de grau ou intensidade e passam a ser de gênero ou de natureza. Certas crenças ou saberes serão científicos não apenas de fato, mas também de direito. Outros talvez o sejam de fato, mas jamais o serão de direito. Essas desigualdades entre as ciências oferecerão à crítica uma oportunidade única para mostrar toda a sua força normativa e terapêutica, fazendo-nos ver, a uma só vez, por que certas crenças não são ciência e por que inevitavelmente nos iludimos a respeito do seu estatuto cognitivo. O caso mais exemplar dessa dupla aplicação da crítica é o da metafísica tradicional. Mas haverá outros. A psicologia e a química são outros dois exemplos que, de um certo modo, deveriam ser tão notórios quanto o da metafísica.

Mas, antes de explicar por que, a exemplo da metafísica, a psicologia e a química deveriam ser (parcialmente) excluídas do âmbito da ciência, vale a pena explorar mais o fato de a força terapêutica e normativa da crítica kantiana ser relegada a um segundo plano diante da expectativa de abertura para "as ciências" e o tratamento isonômico a elas dispensado. A "república das ciências" parece erguer-se à imagem e semelhança da "república das letras", "que não teme a pluralidade de crenças" (Almeida, 2011, p. 120). O enciclopedismo incidental de Kant pode ter sido a fonte da generalização desse ponto de vista. Ocorre que, embora presente, não é o único ponto de vista sobre a ciência eleito por Kant. Ele pretende também apontar as distâncias que determinadas crenças estão de uma ciência digna desse nome. E seus argumentos não são baseados em contingências factuais. Há razões conceituais para que ele recuse o estatuto de ciência a determinados saberes, tais como a metafisica (da tradição), a psicologia e a química, para ficar apenas com os casos mais notórios. Para que as consequências desse fato possam adiante tornarem-se mais evidentes, façamos aqui uma breve divagação sobre esse último ponto.

Num artigo intitulado “A invenção da crise", Ribeiro de Moura considera que "se Kant apresentava a razão como origem de ilusões, o que estava em questão ali era apenas o ‘uso especulativo’ da razão, e não a razão ela mesma, que se comportava muito bem no domínio da física e da matemática, ciências que por si sós nunca teriam suscitado o projeto crítico" (Moura, 2001, p. 185). Não é raro encontrar quem pense como 
Ribeiro de Moura. Não tenciono de modo algum contestar esse juízo sobre a maneira como a razão se comportara, segundo a ótica kantiana, na física e na matemática. Tomoo pelo seu valor de face com o intuito de explorar a consequência tirada desse fato por Ribeiro de Moura e muitos outros comentadores. A consequência a que me refiro é a que a física e a matemática, por si sós, jamais teriam dado ensejo ao projeto crítico. Suspeito que essa seja a fonte mais imediata de uma visão distorcida sobre o significado do envolvimento de Kant com os temas e as questões colocadas pela ciência de seu tempo.

Tomemos o opúsculo Princípios metafísicos da ciência da natureza, que Kant preparou e publicou no intervalo entre as duas edições da primeira Crítica, mais precisamente em 1786. A título de um argumento inicial, vale dizer que o esquecimento a que essa obra foi submetida nos estudos kantianos - até ao menos meados das últimas décadas do século xx - é certamente um dos efeitos da visão de que as palavras de Ribeiro de Moura servem como uma expressão bem acabada. O esquecimento dos Princípios metafísicos decorre em grande parte da ampla aceitação da imagem de que Kant concebera a ciência e a metafísica como empreendimentos teóricos radicalmente distintos, a ponto de que a ciência por si só jamais teria suscitado o projeto crítico, cujo alvo exclusivo é apenas o "uso especulativo" da razão perpetrado pela malfadada metafísica dos modernos.

Creio que há, no mínimo, dois tipos de objeções que se podem levantar sobre tal enfoque interpretativo do projeto crítico kantiano. O primeiro é histórico-genético e consiste em investigar se, de fato, as questões colocadas pelas práticas científicas em curso à época de Kant não foram responsáveis pelo desencadeamento do projeto crítico. Não me servirei desse tipo de objeção. Minhas preocupações e meus motivos ficarão óbvios a seguir. Um segundo tipo de dúvidas, que eu chamaria aqui precariamente de analítico-conceitual, consiste em analisar os conceitos e os argumentos mobilizados por Kant para a consecução do seu projeto crítico e avaliar se, enfim, eles se destinam apenas a disciplinar o "uso especulativo" da razão ou se eles são, além disso, de alguma serventia para a ciência, sobretudo a física e a matemática.

Em princípio, ambos os tipos de objeções são complementares e mutuamente dependentes, nem que o sejam por razões heurísticas. A situação é semelhante àquela descrita pela famosa fórmula de Hanson - "a história da ciência sem a filosofia da ciência é cega... A filosofia da ciência sem a história da ciência é vazia" (Hanson, 1962, p. 580), que, conforme se sabe, é uma paráfrase de outra fórmula ainda mais famosa proferida pelo próprio Kant na primeira Crítica ao defender o uso solidário de conceitos e intuições. Talvez todas as minhas restrições ao projeto de Kant e as ciências possa ser resumido à sua "cegueira" no sentido de Hanson, justamente por privilegiar a abordagem genético-histórica em detrimento de um tratamento conceitual-analítico. 
Mas a cegueira em questão não decorre da ausência de uma filosofia da ciência qualquer. Decorre, sobretudo, da atitude de fechar os olhos para uma filosofia da ciência elaborada pelo próprio Kant, particularmente nos Princípios metafísicos de 1786. Afinal, não se pode dizer que a ausência dessa filosofia da ciência específica não seja ela própria o efeito de uma outra filosofia da ciência de uma matriz específica - de modo geral, daquela matriz que pulveriza a semântica do termo "ciência" em fragmentos tão atomizados que o único sentido possível do termo se refugia no seu uso plural, isto é, em "ciências".

Para saber o que há de tão particularmente determinante em considerar a filosofia da ciência contida nos Princípios metafísicos, basta considerar que ali estão os critérios que Kant elegera para qualquer doutrina que se pretenda como "ciência". Os critérios kantianos podem ser reduzidos a três: (i) seus conceitos devem ser suscetíveis de uma construção na intuição pura; (ii) seus princípios devem possuir o caráter de autênticas leis da natureza conhecidas a priori; (iii) seus diversos juízos, inclusive aqueles conhecidos apenas mediante a experiência, devem constituir um sistema e não uma mera rapsódia ou agregado doutrinário. O conjunto completo desses critérios está exemplarmente realizado em uma única doutrina, que é justamente aquela cujos conceitos, princípios e sistema teórico realizam mais precisamente a "metafísica especial da natureza material" a cuja exposição os Princípios metafísicos são destinados. Essa doutrina é a física newtoniana, com os seus conceitos de matéria, movimento e força, seus princípios de inércia e de ação e reação e, finalmente, seu "sistema de mundo" sustentado na ideia de uma gravitação universal.

Um dos pontos cegos no projeto de Kant e as ciências já salta aos olhos nessa altura. A obra praticamente ignora os Princípios metafísicos como um dos mais importantes e decisivos momentos do diálogo filosófico de Kant com "a pluralidade dos saberes". Apenas um único e exíguo capítulo de Henry Blomme sobre a pretensão à cientificidade da química tem essa obra como seu assunto central, muito embora eles sejam mobilizados mais em virtude dos problemas da química do que propriamente daqueles da física. No prefácio aos Princípios metafísicos, Kant contesta a cientificidade da química por essa não cumprir as condições contidas nos critérios (i) e (ii) acima, ou seja, não possuir uma "parte pura”, requisito indispensável para que uma doutrina possa conter leis da natureza genuínas, isto é, "o conceito da necessidade de todas as determinações de uma coisa, inerentes à sua existência" (Kant, 1990 [1786], p. 6). Em uma palavra, a química não pode ser ciência, pois nela não se pode aplicar a matemática, tomada aqui como uma extensão das condições transcendentais da objetividade, "uma pura teoria da natureza acerca de coisas naturais determinadas (doutrina dos corpos e doutrina da alma) só é possível por meio da matemática; e visto que em toda a teoria da natureza se encontra apenas tanta ciência genuína quanto conhecimento a priori com que aí se 
depare, assim, a teoria da natureza conterá unicamente tanta ciência genuína quanta matemática que nela se pode aplicar" (Kant, 1990 [1786], p. 10). Sendo assim, nada mais coerente que a física newtoniana seja a única a cumprir regiamente esse desideratum. A química pré-lavoisieriana - isto é, a química do flogístico de Becher, Stahl e, finalmente, Priestley -, segundo Kant, estava fadada a permanecer como uma "arte sistemática ou uma teoria experimental", em virtude de a inteligibilidade das ações químicas não se mostrar por meio de conceitos "que se possa construir", limitando-se a conceitos que "não tornam minimamente inteligíveis os princípios dos fenômenos químicos segundo sua possibilidade, porque são incapazes da aplicação da matemática" (Kant, 1990 [1786], p. 10).

Tudo isso está muito bem discutido no capítulo de Kant e as ciências assinado por Henry Blomme. Ele não se limita a analisar as palavras acima de Kant retiradas do prefácio dos Princípios metafísicos, tal como se tornou lugar comum, estendendo suas análises às partes internas do livro e, assim, enfrentando o desafio de esclarecer o diagnóstico negativo com respeito à cientificidade da química em contraponto ao diagnóstico positivo para o caso da física. Blomme elege o princípio da "foronomia" como o mais decisivo para esse efeito. O princípio da foronomia estabelece o movimento como sendo o único conceito pelo qual se pode construir a determinação pura da matéria como algo que oсира um espaço.

$\mathrm{O}$ artigo de Blomme ainda se estende ao capítulo seguinte, dos Princípios metafísicos, sobre a dinâmica, mas sua análise declina em vigor e profundidade, deixando inconcluso o modo como deve ser compreendido o veredicto negativo de Kant na transição de um tratamento meramente mecanicista - fundado no conceito de movimento - para um tratamento decididamente dinamista - fundado no conceito de "forças essenciais da matéria" ou as condições sob as quais a matéria não apenas ocupa um espaço, mas também o preenche. Para Blomme,

a química não poderá se tornar uma verdadeira ciência da natureza enquanto as reações químicas não puderem ser representadas a priori como movimentos: o modo exclusivo pelo qual as matemáticas podem ser a ela aplicadas e os seus princípios empíricos podem ser substituídos por uma parte pura na qual seria fundamentada a necessidade das verdadeiras leis químicas" (p. 167),

e termina de modo lacônico com a seguinte hipótese: "talvez se possa chegar assim a uma determinação da matéria apta a apreender a priori a necessidade das reações químicas" (p. 168).

As pequenas - mas marcantes - deficiências da análise de Blomme refletem a pouca atenção dispensada à realização exemplar do modelo de ciência sustentado pe- 
los Princípios metafísicos. Uma cuidadosa consideração da física mostraria, entre outra coisas, que as condições transcendentais para os objetos da natureza material estabelecidas pela dinâmica tampouco se realizam plenamente nessa ciência. O problema, de maneira muito resumida, seria o fato de as "forças essenciais da matéria" serem refratárias a uma construção na intuição pura, comprometendo assim a incorporação do conceito dessas forças em uma autêntica metafísica da natureza e, consequentemente, em uma ciência genuína da natureza material. A simples consideração desse fato, no mínimo, conferiria um caráter contrafatual à hipótese final de Blomme.

Nem por isso, entretanto, Kant recua em sua escolha da física como sendo a ciência da natureza por excelência. É por essa decisão que se sabe, entre outras coisas, que a psicologia não pode ser uma ciência propriamente dita, tal como ocorre com a química. No caso da psicologia, o problema é a impossibilidade de uma "metafísica especial" que fizesse dos objetos do sentido interno, isto é, da psicologia, a contraparte dos objetos do sentido externo, isto é, da física, cuja possibilidade repousa justamente na certeza da necessidade de uma metafísica especial da natureza material ou dos objetos dos sentidos externos. Dito isso, Kant retira esta conclusão acerca da psicologia ou da "doutrina empírica da alma" cujos desdobramentos terão consequências ainda mais amplas:

[a psicologia] nunca pode ser outra coisa exceto uma teoria natural histórica do sentido interno, e, como tal, tão sistemática quanto possível, isto é, uma descrição natural da alma, mas não uma ciência da alma, nem sequer uma doutrina experimental psicológica; eis também a razão por que é que a esta obra (...) demos o título geral de ciência da natureza, porque tal designação convém-lhe em sentido próprio e, por conseguinte, nenhuma ambiguidade assim se origina (Kant, $199^{\circ}$ [1786], p. 17).

Em Kant et les sciencies, que reserva toda uma seção para o tema da antropologia e da psicologia, apenas uma única vez a restrição à cientificidade da psicologia é mencionada . No seu artigo, "L'antropologie du point de vue pragmatique est-elle une psychologie?", Gilles Blanc-Brude refere-se às palavras de Kant no Prefácio dos Princípios metafísicos acerca da psicologia e delas conclui que "uma teoria natural histórica do sentido interno" aplicada à psicologia deve ser compreendida como uma afirmação do seu caráter sistemático. Vejam que a sistematicidade consta como o terceiro dos três critérios elencados acima para uma ciência genuína da natureza. Por isso, talvez BlancBrude seja tão enfático ao afirmar que 
essa questão do lugar sistemático compromete o destino da psicologia como ciência. Situá-la no interior do sistema crítico significa mantê-la sob a dependência de uma metafísica e de um saber. Situá-la no exterior significa justificar de antemão o desenvolvimento de uma disciplina positiva, mas indiferente aos fins (p. 323).

As palavras de Blanc-Brude, nessa altura, assumem um caráter muito enigmático. Mas é possível que o comentador queira nos fazer crer que a sistematicidade - à qual o destino da cientificidade da psicologia parece estar tão estreitamente ligado significa tão somente a sua inserção no interior do sistema da filosofia crítica kantiano. Nesse caso, a psicologia aproximar-se-ia da metafísica e afastar-se-ia das demais "disciplinas positivas". Ora, se for isso, nada mais contrário às intenções de Kant. Para ele, o movimento de aproximação e afastamento seria justamente o inverso, quanto mais sistemático, tanto mais científico.

Se essa inversão da equação de Blanc-Brude estiver correta, mesmo contrariando a passagem acima dos Princípios metafísicos, é inegável que destacar o seu caráter sistemático representa um ganho expressivo para o enquadramento da psicologia no conjunto das ciências. Sendo assim, não seria de todo equívoco reunir tanto a psicologia quanto a química sob o título de "ciências", mesmo reconhecendo que esse título tem aplicação inequívoca apenas a um único caso, a física, por ser a única a cumprir (quase) integralmente as três condições para uma ciência da natureza. Isso também significa admitir um cumprimento parcial das três condições ou, dito de outro modo, que a sistematicidade possa ser suficiente para, ao menos, colocar um tipo de doutrina no "caminho das ciências". Mas, conforme é amplamente conhecido, os pensamentos de Kant sofreram grandes alterações ao término da segunda edição da primeira Crítica em $17^{8} 7$, sobretudo quando ele passou a cogitar que as determinações do entendimento não deveriam esgotar os componentes constitutivos apriorísticos do nosso conhecimento empírico. Os resultados dessa mudança aparecem na terceira Crítica em 1790, na qual Kant introduz a faculdade do juízo teleológico como responsável pelo fechamento das determinações do entendimento e, assim, pela promoção da máxima unidade sistemática da experiência. A sistematicidade ganha, então, um lugar de destaque no pensamento kantiano, com reflexos na sua concepção da ciência da natureza.

O mais bem estruturado e orientado capítulo de Kant e as ciências trata justamente de uma ciência que ganha lugar de destaque com os novos interesses de Kant nas condições da promoção da máxima unidade sistemática da experiência. Esse capítulo, cujo título é "La place de l'analytique de la biologie dans la philosophie transcendentale", é de autoria de Philippe Huneman. O autor havia publicado em 2008 um estudo rigoroso sobre as fontes biológicas mobilizadas pela terceira Crítica, com ênfa- 
se no conceito de organismo (cf. Huneman, 2008). No seu artigo, Huneman situa o conceito de organismo no centro do esclarecimento do nosso padrão de cientificidade que emerge em torno da exigência de sistematicidade. Mas não é apenas a originalidade da análise de Huneman que merece destaque. Também o merece o cuidado com o qual ele articula suas análises a parcelas mais amplas do corpus kantiano. Para introduzir o novo significado que a sistematicidade adquire para Kant, ele observa que esse conceito tem sua origem na diferença entre

a natureza - isto é, o conjunto de coisas subsumidas a leis, segundo os Princípios metafísicos da ciência da natureza, os quais remetem precisamente aos princípios transcendentais da experiência possível - e a ordem da natureza, segundo a qual as diferentes leis empíricas se combinam em um todo coerente, isto é, a sistematicidade. A própria natureza ergue-se do entendimento (via os princípios do juízo sintético a priori); ela não implica qualquer finalidade e pode-se ter uma natureza sem ordem da natureza. Entretanto, o interesse da razão é precisamente a sistematicidade, sem a qual nenhuma metodologia seria possível (...). Em outros termos, as diferentes exigências de sistematicidade não definem os métodos, mas são o transcendental de toda metodologia. O outro nome da sistematicidade é a finalidade, pois ela significa que a natureza aparece como se estivesse à mercê da nossa faculdade de conhecer. Nesse sentido, essa finalidade é estritamente sinônimo da exigência de sistematicidade da ciência (p. 255-6).

A distinção entre natureza e ordem da natureza vem justamente nos lembrar o quanto as determinações da primeira - basicamente, aquelas decorrentes da aplicações dos critérios (i) e (ii) acima - são insuficientes para uma analítica completa da natureza - sobretudo, daquela que inclui os seres vivos entre os seus objetos potenciais. Isso assegura que pode - e deve - haver uma sistematicidade irredutível à natureza, ela mesma. Para essa sistematicidade de segunda ordem - aquela que conferirá uma unidade orgânica às leis retiradas da experiência -, será preciso mobilizar outras fontes que não apenas a razão pura e os seus princípios a priori. Requer-se para isso a finalidade ou o interesse da razão. O conceito de organismo é, por exemplo, irredutível apenas às determinações do entendimento e não poderia ser, então, construído em uma intuição pura. Para a sua experiência completa, os organismos requerem outras fontes para a sistematicidade, uma vez que não se podem compreendê-los manipulando apenas categorias do entendimento, entre as quais se destaca a causalidade mecânica. Em outras palavras, requer-se uma causalidade teleológica, de tal modo que "mecanismo e teleologia são, então, articulados no juízo biológico completo" (p. 262). 
O artigo de Huneman é um exemplo bem acabado do quanto se ganha na compreensão do envolvimento de Kant com a "pluralidade de saberes" encarando-o também do ponto de vista da filosofia da ciência kantiana. Todavia, dado o escopo do seu artigo, ele não pôde prolongar a explicação do que seria a ciência assentada sobre um conceito robusto de natureza - a física. A lamentar, então, que o livro não ofereça em nenhum de seus outros artigos considerações mais detalhadas sobre a física. Sem essas considerações, o leitor menos informado sobre o assunto permanecerá ignorante do único modelo de ciência que oferece um esquema completo para o princípio do mecanicismo. Conforme tentei mostrar acima, não se trata de uma simples omissão de um entre tantos outros possíveis candidatos à "pluralidade dos saberes" aos quais Kant dedicou sua atenção. A omissão da física significa a omissão dos próprios critérios de cientificidade, sem os quais toda "pluralidade de saberes" degenera-se em pura rapsódia sem nenhuma unidade possível - sobretudo sem a unidade sistemática que é uma exigência para toda e qualquer ciência em particular, mas também para todas elas tomadas como uma totalidade. Sem a ideia dessa unidade, a ciência torna-se uma atividade irremediavelmente cega, senão gratuita e destituída de qualquer interesse para o projeto crítico kantiano.

Mas resta saber por que os organizadores de Kant e as ciências não teriam se dado conta dessa desastrosa omissão. Arrisco dizer que, retomando a divisão que sugeri acima, eles produziram um projeto editorial baseado num enfoque histórico-genético e descuidaram acintosamente da sua contraparte analítico-conceitual. Essa escolha, apesar de seus objetivos declarados, é fortemente inspirada pela concepção de que a física e a matemática são "ciências que por si sós nunca teriam suscitado o projeto crítico" (Moura, 2001, p. 185). Paradoxalmente, isso explica por que nenhuma atenção se dá à física (e, em parte, à própria matemática) em Kant e as ciências. Um livro inteiramente dedicado ao diálogo de Kant com as ciências, mas que omite justamente aquela parte do diálogo que poderia nos conduzir ao âmago do projeto crítico e, assim, interferir decisivamente no modo de compreender esse projeto e suas relações de dependência mútua com a "pluralidade de saberes". Submeter o diálogo a uma reconstrução meramente histórico-genética pode ser ilustrativo, mas não será nada esclarecedor, se não for também reconstruído de modo analítico - conceitual. Valem aqui as palavras do próprio Kant após considerar o projeto enciclopedista de D'Alembert, na seção 4. da Introdução da Lógica: "há de se tornar merecedor da História como um gênio quem a compreender sob ideias capazes de permanecerem para sempre” (Kant, 1992 [1800], p. 61).

Nesse aspecto particular, Kant e as ciências diverge acentuadamente de outras publicações sobre o mesmo tema surgidas nos últimos anos. No prefácio da sua obra mais recente, Friedman, por exemplo, defende que seja atribuído um papel central aos 
Princípios metafísicos dentro do período crítico da filosofia kantiana. "Estou convencido, em particular, de que não é possível compreender adequadamente esse período crítico sem dedicar uma atenção detalhada e intensiva ao comprometimento de Kant com a ciência newtoniana" (Friedman, 2013, p. xI). Enunciando de modo afirmativo a relação defendida por Friedman, podemos dizer que uma análise do comprometimento de Kant com a ciência newtoniana permite uma melhor compreensão da filosofia crítica kantiana. E isso, pelo que defendi até aqui, justifica-se não apenas pelo que a ciência newtoniana tem em comum com as demais ciências inclusas na pluralidade dos saberes que despertaram o interesse de Kant. Mas, ao contrário, pelo que ela tem de particular, que são, em última análise, os nexos que prendem o interesse de Kant pelas ciências ao restante do edifício crítico.@

\section{Eduardo Salles de Oliveira Barra \\ Departamento de Filosofia, Universidade Federal do Paraná, Brasil. eduardosobarra@gmail.com}

\section{Science and Kantian critical project}

\section{REFERÊNGIAS BIBLIOGRÁFIGAS}

Adickes, E. Kant als Naturforscher Berlin: De Gruyter, 1924. 2 v.

Almeida, M. C. O elogio da tolerância em Pierre Bayle. Cadernos Espinosanos, 24, p. 115-39, 2011.

Buchdahl, G. Metaphysics and philosophy of science. The classical origins, Descartes to Kant. Laham: University

Press of America, 1988 [1969].

Kant and the dynamics of reason. Oxford: Blackwell, 1992.

Butts, R. E. (Ed.). Kant's philosophy of physical science. Dordrecht: D. Reidel, 1986.

Friedman, M. Kant and the exact sciences. Cambridge, MA: Harvard University Press, 1992.

Kant's construction of nature: a reading of the metaphysical foundations of natural science. Cambridge:

Cambridge University Press, 2013.

Hanson, N. R. The irrelevance of history of science to philosophy of science. The Journal of Philosophy, 59 ,

p. 574-86, 1962.

Huneman, P. Métaphysique et biologie: Kant et la constitution du concept d'organisme. Paris: Kimé, 2008.

Kant, I. Princípios metafísicos da ciência da natureza. Tradução A. Morão. Lisboa: Edições 70, 1990 [1786]. Lógica. Tradução G. A. de Almeida. Rio de Janeiro: Tempo Brasileiro, 1992 [180o].

Moura, C.A. R. de.Ainvenção da crise. In: Racionalidade e crise. São Paulo/Curitiba: Discurso Edi-

torial/Editora UFPR, 2001. p. 185-205.

Vuillemin, J. Physique et métaphysique kantiennes. Paris: PUF, 1955.

Watkins, E. Kant and the sciences. Oxford: Oxford University Press, 2001.

Kant and the metaphysics of causality. Cambridge: Cambridge University Press, 2005. 